\title{
Stereotactic radiosurgery for cerebral arteriovenous malformations: evaluation of long-term outcomes in a multicenter cohort
}

\author{
Robert M. Starke, MD, MSc, ${ }^{1}$ Hideyuki Kano, MD, ${ }^{2}$ Dale Ding, MD, ${ }^{1}$ John Y. K. Lee, MD, ${ }^{3}$ \\ David Mathieu, MD, ${ }^{4}$ Jamie Whitesell, ${ }^{3}$ John T. Pierce, MS, ${ }^{3}$ Paul P. Huang, MD, ${ }^{5}$ \\ Douglas Kondziolka, MD, ${ }^{5}$ Chun-Po Yen, MD, ${ }^{1}$ Caleb Feliciano, MD, ${ }^{6}$ \\ Rafael Rodgriguez-Mercado, MD, ${ }^{6}$ Luis Almodovar, MD, ${ }^{6}$ Daniel R. Pieper, MD, ${ }^{7}$ \\ Inga S. Grills, MD, ${ }^{7}$ Danilo Silva, MD, ${ }^{8}$ Mahmoud Abbassy, MD, ${ }^{8}$ Symeon Missios, MD, ${ }^{8}$ \\ Gene H. Barnett, MD, ${ }^{8}$ L. Dade Lunsford, MD, ${ }^{2}$ and Jason P. Sheehan, MD, PhD ${ }^{1}$
}

\begin{abstract}
${ }^{1}$ Department of Neurosurgery, University of Virginia, Charlottesville, Virginia; ${ }^{2}$ Department of Neurosurgery, University of Pittsburgh; ${ }^{3}$ Gamma Knife Center, University of Pennsylvania, Philadelphia, Pennsylvania; ${ }^{4}$ Department of Neurosurgery, University of Sherbrooke, Quebec, Canada; ${ }^{5}$ Gamma Knife Center, New York University, New York, New York; ${ }^{6}$ Department of Neurosurgery, University of Puerto Rico, San Juan, Puerto Rico; ${ }^{7}$ Gamma Knife Center, Beaumont Health System, Royal Oak, Michigan; and ${ }^{8}$ Department of Neurosurgery, Cleveland Clinic Foundation, Cleveland, Ohio
\end{abstract}

\begin{abstract}
OBJECTIVE In this multicenter study, the authors reviewed the results following Gamma Knife radiosurgery (GKRS) of cerebral arteriovenous malformations (AVMs), determined predictors of outcome, and assessed predictive value of commonly used grading scales based upon this large cohort with long-term follow-up.

METHODS Data from a cohort of 2236 patients undergoing GKRS for cerebral AVMs were compiled from the International Gamma Knife Research Foundation. Favorable outcome was defined as AVM obliteration and no posttreatment hemorrhage or permanent symptomatic radiation-induced complications. Patient and AVM characteristics were assessed to determine predictors of outcome, and commonly used grading scales were assessed.

RESULTS The mean maximum AVM diameter was $2.3 \mathrm{~cm}$, with a mean volume of $4.3 \mathrm{~cm}^{3}$. A mean margin dose of 20.5 Gy was delivered. Mean follow-up was 7 years (range $1-20$ years). Overall obliteration was $64.7 \%$. Post-GRKS hemorrhage occurred in 165 patients (annual risk 1.1\%). Radiation-induced imaging changes occurred in 29.2\%; 9.7\% were symptomatic, and $2.7 \%$ had permanent deficits. Favorable outcome was achieved in $60.3 \%$ of patients. Patients with prior nidal embolization (OR 2.1, $p<0.001$ ), prior AVM hemorrhage (OR 1.3, $p=0.007$ ), eloquent location (OR 1.3, $p=0.029$ ), higher volume (OR 1.01, $p<0.001$ ), lower margin dose (OR 0.9, $p<0.001$ ), and more isocenters (OR 1.1, $p=$ 0.011 ) were more likely to have unfavorable outcomes in multivariate analysis. The Spetzler-Martin grade and radiosurgery-based AVM score predicted outcome, but the Virginia Radiosurgery AVM Scale provided the best assessment.

CONCLUSIONS GKRS for cerebral AVMs achieves obliteration and avoids permanent complications in the majority of patients. Patient, AVM, and treatment parameters can be used to predict long-term outcomes following radiosurgery. http://thejns.org/doi/abs/10.3171/2015.9.JNS151311

KEY WORDS stereotactic radiosurgery; Gamma Knife; arteriovenous malformation; hemorrhage; embolization; surgery; radiation; grading; scale; complication; outcome; visual disorders
\end{abstract}

A LTHOUGH cerebral arteriovenous malformations (AVMs) are uncommon, ${ }^{1,36}$ they often present in young patients, leading to significant overall morbidity and even mortality. ${ }^{19}$ Despite the controversial benefit of intervention for unruptured AVMs, radiosurgery has been used to achieve safe and complete obliteration of nidi that are often noted to entail high risks for hemorrhage and treatment with resection. The outcomes of AVM radiosurgery take several years to become apparent, and patients are at continued risk of hemorrhage prior to complete

ABBREVIATIONS ARUBA = A Randomized Trial of Unruptured Brain AVMs; AUC = area under the receiver operating characteristic curve; $A V M=$ arteriovenous malformation; GKRS = Gamma Knife radiosurgery; $\mathrm{mHR}=$ hazard ratio in the presence of mortality risk; RBAS = radiosurgery-based AVM score (modified version); SAIVM = Scottish Audit of Intracranial Vascular Malformations; VRAS = Virginia Radiosurgery AVM Scale.

SUBMITTED June 6, 2015. ACCEPTED September 9, 2015.

INCLUDE WHEN CITING Published online March 4, 2016; DOI: 10.3171/2015.9.JNS151311. 
obliteration. A number of patient and AVM characteristics have been suggested to predict outcome following radiosurgery, but studies are often limited due to small numbers of patients, single institution biases, and/or limited followup. In this multicenter study, we reviewed the results following Gamma Knife radiosurgery (GKRS) of cerebral AVMs treated across 2 decades, determined predictors of outcome, and assessed the predictive value of commonly used grading scales based upon this large cohort with long clinical follow-up.

\section{Methods}

\section{Patient Population}

Eight medical centers participating in the International Gamma Knife Research Foundation obtained individual institutional review board approvals to participate in this study. A total of 2236 patients were identified with cerebral AVMs treated with GKRS from 1988 to 2013. At each center, retrospective clinical outcome analysis of patients was performed. The following centers contributed data for this study: the University of Pittsburgh (758 patients), Cleveland Clinic (192 patients), New York University (103 patients), University of Sherbrooke (50 patients), University of Pennsylvania (33 patients), University of Puerto Rico (26 patients), Beaumont Health System (62 patients), and the University of Virginia (1012 patients).

The records of AVM patients who underwent Gamma Knife (Elekta AB) radiosurgery (GKRS) between 1988 and 2013 were evaluated by clinicians at each center for study inclusion. A database with selected variables was created and sent to all participating centers. Participating centers reviewed the medical records of their patients, entered the data in the spreadsheet, and removed all patient identifiers from the database. Pooled and de-identified data were screened for errors by an independent third party. Any uncertainties or ambiguities in the data were addressed by the contributing center. Afterward, data were transmitted to the first and senior authors who, along with their coauthors, developed this report.

Patients were included in the study if they had a cerebral AVM treated with GKRS. For inclusion, patients were required to have undergone a minimum of 12 months of neuroimaging and clinical follow-up after GKRS, but patients who suffered a complication within 12 months of treatment were also included. Patients with volume-staged radiosurgery were excluded.

\section{Radiosurgical Technique}

The Gamma Knife models U, B, C, 4C, or Perfexion were used, depending on the technology available at the time of GKRS for each participating center. The radiosurgery procedure began with the application of the Leksell model G stereotactic frame (Elekta AB), using local anesthetic supplemented by additional sedation as needed. After stereotactic frame placement, high-resolution, stereotactic MRI was performed. In cases for which MRI was not feasible or when MRI distortion was a concern, a stereotactic CT scan was obtained. Thin-slice axial and/ or coronal plane images were obtained after intravenous contrast administration. Stereotactic cerebral angiography was incorporated into treatment planning for nidus definition and dose planning. Radiosurgery dose planning was then performed by the neurosurgeon in conjunction with a radiation oncologist and medical physicist.

\section{Clinical and Neuroimaging Follow-Up}

Clinical and neuroimaging evaluations were generally performed at follow-up intervals of 6 months for the first 2 years after radiosurgery and then yearly afterward. When there was no nidus visible on MRI, the patient underwent angiography to confirm the obliteration of the nidus. All images were analyzed by both a neurosurgeon and a neuroradiologist. Patients were instructed to continue MRI follow-up every 1-5 years to monitor for long-term complications, even after their angiogram demonstrated complete AVM obliteration. For those patients for whom MRI was contraindicated (e.g., a cardiac pacemaker present), CT was performed instead. Whenever feasible, patients underwent follow-up neurological examination and neuroimaging at the respective treating center. However, because participating institutions represented tertiary referral centers, some patients underwent follow-up evaluations by their local physicians. For such patients, clinical notes and actual neuroimaging studies (i.e., not just the radiological reports) were received and reviewed by the treating clinicians who performed the GKRS procedure. The follow-up images were compared with the images obtained at the time of GKRS. AVM dimensions were assessed in the axial, sagittal, and coronal planes in relation to comparable measurements on the GKRS neuroimaging studies.

\section{Statistical Analysis}

Data are presented as median or mean and range for continuous variables, and as frequency and percentage for categorical variables. Calculations of normality were assessed graphically and statistically. Statistical analyses of categorical variables were carried out using chi-square and Fisher's exact test associations as appropriate. Statistics of means were carried out using the unpaired Student t-test, both with and without equal variance (Levene test) as necessary, and Wilcoxon rank-sum tests when variables were not normally distributed. Favorable outcome was defined as AVM obliteration and no posttreatment hemorrhage or permanent symptomatic complications following treatment. Patient, AVM, and treatment characteristics were assessed in univariate analysis to test covariates predictive of outcome. Clinically significant variables and interaction expansion covariates were both further assessed in multivariable analysis as deemed relevant. Factors predictive in univariate analysis $(\mathrm{p}<0.15)$ were entered into multivariate logistic regression analysis models both with and without treatment characteristics. ${ }^{4}$ Eloquence was assessed according to the Spetzler-Martin grading scale, location was defined according to the updated ${ }^{29}$ version of the modified radiosurgery-based AVM score (RBAS), and the Virginia Radiosurgery AVM Scale (VRAS) was defined as originally described (Table 1). ${ }^{39}$ Additionally, competing risk survival analysis of AVM-free obliteration was calculated using the modified Kaplan-Meier method and Gray's method. ${ }^{17}$ After confirmation of the assump- 
TABLE 1. Commonly used systems for grading AVMs

\begin{tabular}{|c|c|c|}
\hline Grading System \& Characteristic & $\begin{array}{l}\text { Points } \\
\text { Assigned }\end{array}$ & Coefficient \\
\hline \multicolumn{3}{|l|}{ Spetzler-Martin grade } \\
\hline \multicolumn{3}{|l|}{ Diameter (cm) } \\
\hline Small $(<3)$ & 1 & \\
\hline Medium (3-6) & 2 & \\
\hline Large $(>6)$ & 3 & \\
\hline \multicolumn{3}{|l|}{ Eloquence* $^{*}$} \\
\hline No & 0 & \\
\hline Yes & 1 & \\
\hline \multicolumn{3}{|l|}{ Venous drainage } \\
\hline Superficial only & 0 & \\
\hline Deep & 1 & \\
\hline \multicolumn{3}{|l|}{ RBAS score $\dagger$} \\
\hline Vol $\left(\mathrm{cm}^{3}\right)$ & & 0.1 \\
\hline Patient age (yrs) & & 0.02 \\
\hline Location $\ddagger$ & & 0.3 \\
\hline \multicolumn{3}{|c|}{$\begin{array}{l}\text { Hemispheric, corpus callosum, cerebel- } \\
\quad l a r=0\end{array}$} \\
\hline \multicolumn{3}{|c|}{ Basal ganglia, thalamus, brainstem $=1$} \\
\hline \multicolumn{3}{|l|}{ VRAS } \\
\hline \multicolumn{3}{|l|}{ Vol $\left(\mathrm{cm}^{3}\right)$} \\
\hline 1 & 0 & \\
\hline $2-4$ & 1 & \\
\hline$>4$ & 2 & \\
\hline \multicolumn{3}{|l|}{ History of hemorrhage } \\
\hline No & 0 & \\
\hline Yes & 1 & \\
\hline \multicolumn{3}{|l|}{ Eloquence } \\
\hline No & 0 & \\
\hline Yes & 1 & \\
\hline
\end{tabular}

* Sensorimotor, language, or visual cortex; hypothalamus or thalamus; internal capsule; brainstem; cerebellar peduncles; or cerebellar nuclei.

$\dagger$ RBAS $=(0.1)($ volume $)+(0.02)$ (patient age $)+(0.3)($ location $)$

$\ddagger$ In the original RBAS, frontal and temporal location received 0 points; parietal, occipital, intraventricular, corpus callosum, and cerebellar received 1 point; and basal ganglia, thalamus, and brainstem received 2 points.

tion of proportional hazards, factors predictive of obliteration $(\mathrm{p}<0.15)$ were entered into modified multivariate Cox regression analysis to assess hazard ratios in the presence of competing mortality risk (mHR) ${ }^{14}$ Multivariate regression models and commonly used grading scales were assessed using area under the receiver operating characteristic curve (AUC). Youden indices were calculated to determine cutoffs for the dichotomized continuous variable margin dose (Gy) that yielded the optimal discrimination of radiation-induced changes. A p value of less than or equal to 0.05 was considered statistically significant.

\section{Results}

Of the 2236 patients with cerebral AVMs, the mean age at the time of treatment was 36 years, and $49.6 \%$ were fe- male (Table 2). The mean maximum AVM diameter was $2.3 \mathrm{~cm}$, with a mean volume of $4.3 \mathrm{~cm}^{3}$. At the time of GKRS, the AVM volume was $0-2 \mathrm{~cm}^{3}$ in $35.3 \%$ of patients, $2-4 \mathrm{~cm}^{3}$ in $26.7 \%$, and greater than $4 \mathrm{~cm}^{3}$ in $37.0 \%$. Prior subtotal microsurgical resection was performed in $4.9 \%$ of patients, $1.1 \%$ had a history of CSF diversion, $8.5 \%$ had a history of radiotherapy, and $21.5 \%$ had a history of embolization.

The mean prescription dose delivered to the AVM margin was 20.5 Gy (median $20 \mathrm{~Gy}$, range 5-36 Gy; Table 3). The mean prescription isodose line was $54.0 \%$ (median $50 \%$, range $30 \%-100 \%$ ). Most of the dose plans involved a multi-isocentric approach; a mean of 3.6 isocenters (median 3, range 1-43) were used.

\section{Assessment of Obliteration}

The mean follow-up after GKRS was 7 years (range 0.5-20 years). Overall, the rate of confirmation of MRI or angiographic obliteration was $64.7 \%$ at last follow-up. Complete angiographic obliteration was confirmed in $50.9 \%$ of cases, and MRI obliteration was present in another $13.8 \%$ of patients. The Kaplan-Meier actuarial rate of obliteration is demonstrated in Fig. 1. Patients with an AVM volume less than $4 \mathrm{~cm}^{3}$ and treated with more than 18 Gy were significantly more likely to have obliteration (77.3\%) than those with an AVM greater than $4 \mathrm{~cm}^{3}$ and treated with less than 18 Gy $(48.3 \%, \mathrm{p}<0.001)$. Independent predictors of overall obliteration in multivariate analysis were younger age (mHR 0.99, 95\% CI 0.99-0.99, p < 0.001 ), lower nidus volume (mHR $0.96,95 \%$ CI $0.94-0.98$, $\mathrm{p}<0.001$ ), increasing year from when GKRS was performed (mHR 1.1, 95\% CI 1.0-1.1, p < 0.001), and higher margin dose (mHR 1.1, 95\% CI 1.0-1.1, p < 0.001).

\section{Postradiosurgical Complications}

Post-GRKS hemorrhage occurred in 165 patients in 15,362 years of follow-up, for an annual risk of $1.1 \%$ during the latency period. No hemorrhages were observed in patients with angiographic confirmation of obliteration. Patients with a history of hemorrhage were more likely to have post-GRKS hemorrhage (8.6\%) than patients without a history of hemorrhage $(6.3 \%, \mathrm{p}=0.036)$.

Radiation-induced imaging changes, consistent with transient or permanent increased perinidal T2-weighted changes on follow-up MRI, were radiologically evident in $29.2 \%$ of patients, symptomatic in $9.4 \%$, and permanent in $2.7 \%$. Independent predictors of any radiation-induced changes in multivariate analysis were a history of prior radiotherapy (OR 2.2, 95\% CI 1.5-3.2, p < 0.001), increasing nidus maximum diameter (OR 1.1, 95\% CI 1.0-1.3, $\mathrm{p}$ $<0.020$ ), history of hemorrhage (OR 1.6, 95\% CI 1.3-2.1, $\mathrm{p}<0.001$ ), increasing maximum follow-up (OR 1.0, 95\% CI 1.0-1.1, p < 0.001), and increasing margin dose (OR 1.1, $95 \%$ CI 1.0-1.1, p = 0.014). Youden indices demonstrated that patients treated with a margin dose greater than 24 Gy were at greatest risk of developing radiation-induced changes (OR 1.8, 95\% CI 1.3-2.3, p < 0.001). Similarly, patients treated with greater than 24 Gy were also significantly more likely to experience symptomatic (OR 1.9, 95\% CI 1.3-2.8, $\mathrm{p}=0.001$ ) and permanent radiation-in- 
TABLE 2. Patient and AVM characteristics*

\begin{tabular}{|c|c|}
\hline Characteristic & Value \\
\hline Male sex & $1127(50.4)$ \\
\hline \multicolumn{2}{|l|}{ Age in yrs } \\
\hline Mean \pm SD & $36.0 \pm 16.5$ \\
\hline Median & 35 \\
\hline Range & $2.8-99$ \\
\hline \multicolumn{2}{|l|}{ Presentation } \\
\hline Headache & $342(12.6)$ \\
\hline Seizure & $516(19.1)$ \\
\hline Neurological alteration & $782(29.0)$ \\
\hline Hemorrhage & $1060(39.3)$ \\
\hline \multicolumn{2}{|l|}{ Location } \\
\hline Frontal, temporal & $770(34.9)$ \\
\hline Parietal, occipital, corpus callosum & $772(32.7)$ \\
\hline Cerebellum & $518(23.5)$ \\
\hline Insula & $32(1.5)$ \\
\hline Thalamus, basal ganglia, brainstem & $264(26.1)$ \\
\hline Intraventricular & $7(0.3)$ \\
\hline Associated aneurysm & $259(11.6)$ \\
\hline \multicolumn{2}{|l|}{ Max diameter in $\mathrm{cm}$} \\
\hline Mean \pm SD & $2.3 \pm 1.2$ \\
\hline Median & 2.2 \\
\hline Range & $0.6-5.3$ \\
\hline \multicolumn{2}{|l|}{ Vol in $\mathrm{cm}^{3}$} \\
\hline Mean \pm SD & $4.3 \pm 4.9$ \\
\hline Median & 3 \\
\hline Range & $0.1-24$ \\
\hline Deep venous drainage & $1231(55.7)$ \\
\hline Eloquence & $1537(69.6)$ \\
\hline \multicolumn{2}{|l|}{ Diameter } \\
\hline $0-3 \mathrm{~cm}$ & $1688(75.4)$ \\
\hline $3-6 \mathrm{~cm}$ & $527(23.8)$ \\
\hline$>6 \mathrm{~cm}$ & $16(0.7)$ \\
\hline \multicolumn{2}{|l|}{ Spetzler-Martin grade } \\
\hline Mean \pm SD & $2.5 \pm 0.8$ \\
\hline Median & 3 \\
\hline Range & $1-5$ \\
\hline \multicolumn{2}{|l|}{ Distribution } \\
\hline 1 & $236(10.7)$ \\
\hline II & $835(37.8)$ \\
\hline III & $918(41.6)$ \\
\hline IV & $205(9.3)$ \\
\hline V & $15(0.7)$ \\
\hline \multicolumn{2}{|l|}{ VRAS score } \\
\hline Mean \pm SD & $2.2 \pm 1.2$ \\
\hline Median & 2 \\
\hline Range & $0-4$ \\
\hline \multicolumn{2}{|l|}{ Distribution } \\
\hline 0 & $163(7.4)$ \\
\hline
\end{tabular}

CONTINUED IN NEXT COLUMN
» CONTINUED FROM PREVIOUS COLUMN

TABLE 2. Patient and AVM characteristics*

\begin{tabular}{cc}
\hline \multicolumn{1}{c}{ Characteristic } & Value \\
\hline VRAS score (continued) & \\
\hline Distribution (continued) & $556(25.2)$ \\
\hline 1 & $533(24.2)$ \\
\hline 2 & $585(26.5)$ \\
\hline 3 & $370(16.8)$ \\
\hline 4 & $1.4 \pm 0.6$ \\
\hline RBAS & 1.3 \\
\hline Mean \pm SD & $0.4-3.5$ \\
\hline Median & \\
\hline Range & $463(21.5)$ \\
\hline History & $191(8.5)$ \\
\hline Embolization & $110(4.9)$ \\
\hline Radiation & $25(1.1)$ \\
\hline AVM surgery
\end{tabular}

* Values are number of patients (\%) unless otherwise indicated.

duced changes (OR 2.4, 95\% CI 1.1-5.4, $\mathrm{p}=0.028)$. When we controlled for independent predictors in multivariate analysis, patients treated with a margin dose of greater than 24 Gy were 1.5 times more likely to develop radiation-induced changes $(95 \%$ CI 1.1-2.1, $\mathrm{p}=0.004)$.

\section{Assessment of Outcome}

Favorable outcome (AVM obliteration without postradiosurgery hemorrhage or permanent GKRS-associated symptoms) was achieved in $60.3 \%$ of patients. The univariate logistic regression analysis for predictors of unfavorable outcome is detailed in Table 4. Independent predictors of unfavorable outcome in the multivariate logistic regression analysis were higher nidus volume (OR 1.1, 95\% CI $1.0-1.2, \mathrm{p}<0.001$ ), prior AVM hemorrhage (OR 1.4, 95\% CI 1.2-1.7, p < 0.001), prior embolization (OR 2.0, 95\% CI $1.6-2.5, \mathrm{p}<0.001$ ), eloquent AVM location (OR 1.3, 95\% CI $1.0-1.6, p=0.009)$, higher number of isocenters (OR $1.1,95 \%$ CI 1.0-1.1, $\mathrm{p}=0.011)$, and lower margin dose (OR $0.87,95 \%$ CI $0.84-0.90, p<0.001$; Table 4).

The Spetzler-Martin grade $(\mathrm{p}<0.001$, AUC 0.60$)$ and RBAS ( $<0.001$, AUC 0.62) predicted outcome, but the VRAS score provided the best assessment $(\mathrm{p}<0.001$, AUC 0.67) (Fig. 2).

\section{Discussion}

AVMs pose a significant lifetime risk of intracranial

TABLE 3. Summary of radiosurgery treatment parameters

\begin{tabular}{lrc}
\hline \multicolumn{1}{c}{ Characteristic } & Mean \pm SD & Median (range) \\
\hline Margin dose, Gy & $20.5 \pm 3.7$ & $20(10-36)$ \\
\hline Max dose, Gy & $38.6 \pm 7.4$ & $40(20-60)$ \\
\hline No. of isocenters & $3.7 \pm 3.6$ & $3(1-18)$ \\
\hline Isodose line, $\%$ & $53.8 \pm 9.6$ & $50(45-90)$ \\
\hline
\end{tabular}




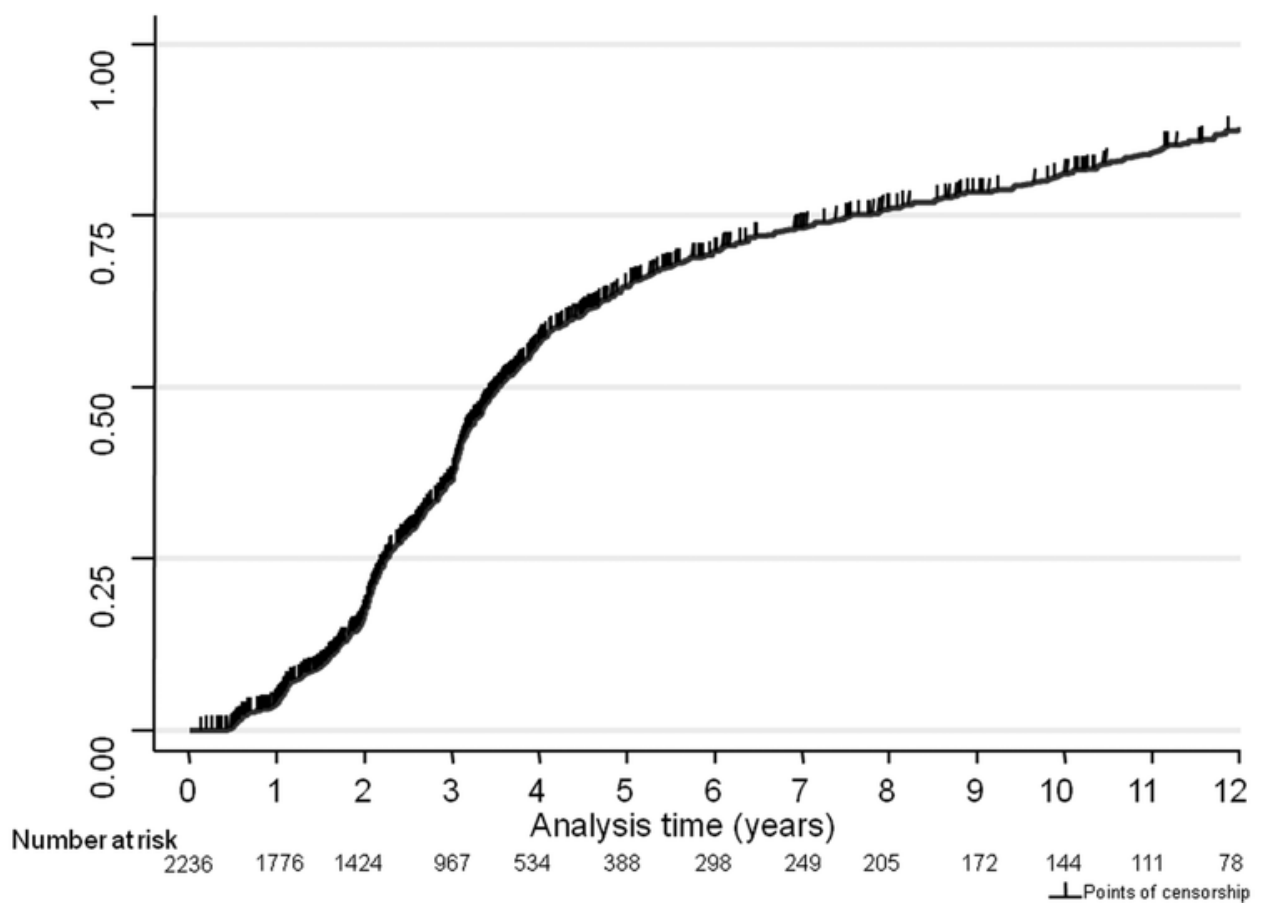

FIG. 1. Modified Kaplan-Meier plot showing AVM obliteration rates over time following radiosurgery.

hemorrhage to affected patients, owing to their relatively young age at presentation and $2 \%-4 \%$ annual hemorrhage risk. ${ }^{2,9}$ Ruptured AVMs require treatment to prevent subsequent hemorrhage, which occurs at a higher rate after the initial hemorrhage. ${ }^{18,37}$ In contrast, the management of unruptured AVMs is currently a subject of intense debate.
Two recent prospective analyses comparing intervention to medical management for patients with unruptured AVMs, A Randomized Trial of Unruptured Brain AVMs (ARUBA) and the Scottish Audit of Intracranial Vascular Malformations (SAIVM) Study, showed significantly worse outcome with intervention that primarily repre-

TABLE 4. Predictors of overall unfavorable outcome*

\begin{tabular}{|c|c|c|c|c|c|c|}
\hline \multirow[b]{2}{*}{ Characteristic } & \multicolumn{3}{|c|}{ Univariate } & \multicolumn{3}{|c|}{ Multivariate } \\
\hline & OR & $95 \% \mathrm{Cl}$ & $p$ Value & OR & $95 \% \mathrm{Cl}$ & $\mathrm{p}$ Value \\
\hline Male sex & 1.010 & $0.850-1.202$ & 0.906 & - & - & - \\
\hline Age at GKRS & 1.003 & $0.997-1.008$ & 0.335 & - & - & - \\
\hline Yr of GKRS & 1.008 & $0.995-1.021$ & 0.227 & - & - & - \\
\hline Yr of diagnosis & 0.992 & $0.984-1.007$ & 0.072 & - & - & - \\
\hline Time diagnosis to GKRS & 1.001 & $0.999-1.002$ & 0.203 & - & - & - \\
\hline Prior radiotherapy & 0.810 & $0.657-1.000$ & 0.049 & 0.696 & $0.475-1.016$ & 0.061 \\
\hline Prior surgery & 0.791 & $0.617-1.016$ & 0.066 & 1.019 & $0.696-1.494$ & 0.921 \\
\hline Prior embolization & 2.331 & $1.889-2.876$ & $<0.001$ & 1.992 & $1.598-2.485$ & $<0.001$ \\
\hline Prior AVM hemorrhage & 1.608 & $1.348-1.917$ & $<0.001$ & 1.444 & $1.181-1.740$ & $<0.001$ \\
\hline Max diameter & 1.755 & $1.592-1.935$ & $<0.001$ & - & - & - \\
\hline Vol & 1.159 & $1.129-1.189$ & $<0.001$ & 1.144 & $1.113-1.175$ & $<0.001$ \\
\hline Associated aneurysm & 1.402 & $1.072-1.833$ & 0.014 & 1.300 & $0.962-1.757$ & 0.088 \\
\hline Eloquent location & 1.371 & $1.132-1.662$ & 0.001 & 1.322 & $1.072-1.630$ & 0.009 \\
\hline Deep venous drainage & 1.087 & $0.913-1.294$ & 0.350 & - & - & - \\
\hline Max follow-up & 0.999 & $0.998-1.001$ & 0.783 & - & - & - \\
\hline Max dose & 0.939 & $0.927-0.950$ & $<0.001$ & 1.025 & $0.934-1.123$ & 0.602 \\
\hline Margin dose & 0.832 & $0.811-0.856$ & $<0.001$ & 0.867 & $0.838-0.898$ & $<0.001$ \\
\hline Isodose & 0.981 & $0.972-0.991$ & $<0.001$ & 1.016 & $0.963-1.071$ & 0.549 \\
\hline No. of isocenters & 1.053 & $1.025-1.082$ & $<0.001$ & 1.048 & $1.010-1.087$ & 0.011 \\
\hline
\end{tabular}

\footnotetext{
* Boldface type indicates independent predictors of unfavorable outcome.
} 


\section{Spetzler Martin Score}
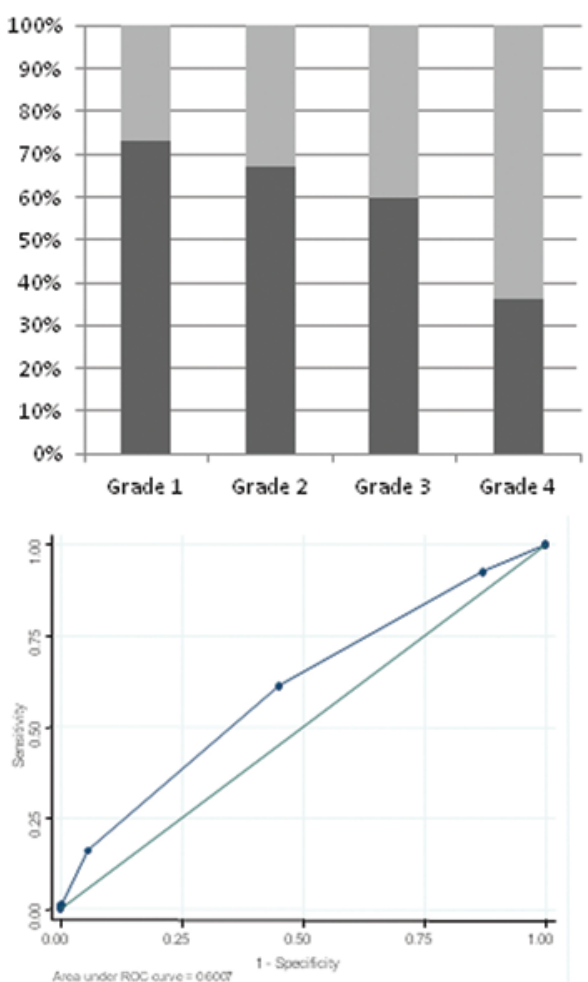

\section{Radiosurgery-Based Grading Scale Radiosurgery AVM Scale}
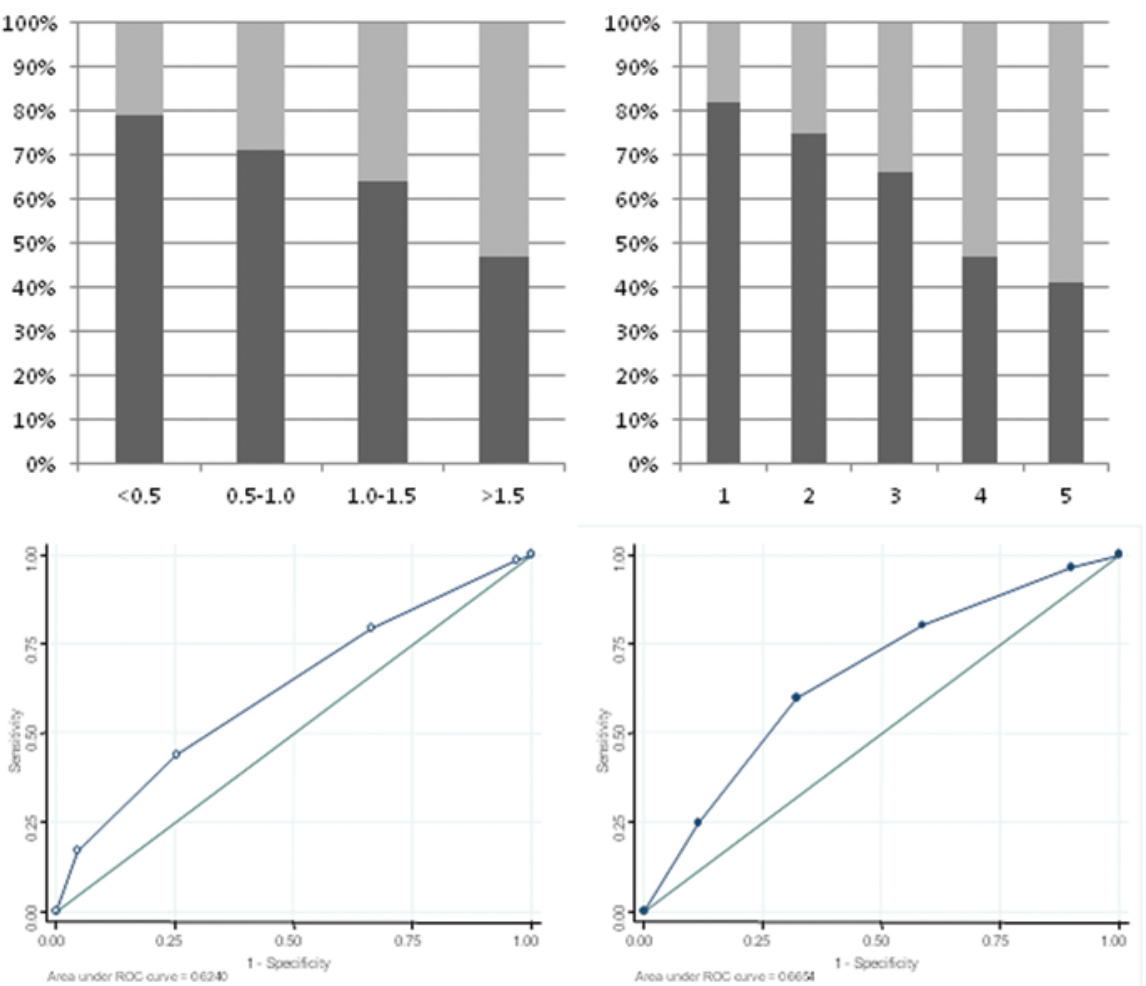

FIG. 2. Graphs showing prediction of outcome according to the Spetzler-Martin grade, RBAS, and VRAS. ROC = receiver operating characteristic. Figure is available in color online only.

sented endovascular embolization. ${ }^{3,26}$ Despite the major methodological and short-term analyses of the results of both aforementioned studies as well as ample previously published data related to the risks of bleeding and death from an untreated AVM, enthusiasm for aggressive management of these patients has been reported to have waned among physician gatekeepers. . $^{32,33,38}$ Therefore, defining long-term outcomes is crucial to justifying AVM intervention to patients and physicians alike.

\section{AVM Intervention With Gamma Knife Radiosurgery}

Although resection remains the frontline management designed to obtain early obliteration of AVMs, GKRS has been widely accepted as an effective alternative to surgery for patients with smaller volume AVMs or with AVMs deeply located or in eloquent areas. ${ }^{20,39}$ GKRS causes progressive AVM obliteration by inducing endothelial injury, myointimal proliferation, collagen deposition, vessel hyalinization, and eventual vascular thrombosis and occlusion. ${ }^{34}$ This process typically takes place over a period of 2-3 years, although realization of nidal obliteration on neuroimaging occurs at widely varying intervals due to differences in the intervals of radiological follow-up. In this study, the overall obliteration rate was $65 \%$, and the mean time to documentation of obliteration was 46 months after initial GKRS.

In the same manner as obliteration, complications such as radiation-induced changes and latency period hemorrhage also occur in a delayed fashion after GKRS. ${ }^{29,39}$ Radiological evidence of radiation-induced changes generally precedes nidal obliteration, typically occurring at an interval of 6-18 months after GKRS. ${ }^{43}$ In this study, the rates of symptomatic and permanent radiation-induced changes were $9 \%$ and $3 \%$, respectively, which were similar to those reported in prior single-center series. ${ }^{15,43}$ Patients treated with greater than 24 Gy were at the highest risk of radiation-induced changes. In general, GKRS has not been shown to significantly affect the natural hemorrhage risk of an AVM. ${ }^{25}$ However, in our analysis, the annual hemorrhage rate during the latency period was low at $1.1 \%$. Thus, GKRS may confer partial protection from AVM rupture during the time interval before obliteration is confirmed, but this finding may also be a reflection of selection and/ or follow-up bias, because latency hemorrhage rates have been variably reported in the literature.

In the context of ARUBA and the SAIVM prospective AVM study, our findings suggest that radiosurgery confers a durable benefit over conservative management for 
appropriately selected patients with unruptured AVMs. However, one should note that $39 \%$ of patients in this study presented with AVM hemorrhage. Additionally, a number of the patients with unruptured AVMs underwent prior intervention with embolization (22\%), fractionated external beam radiotherapy (9\%), and/or resection (5\%), and would thus be ineligible for ARUBA. The differences in patient baseline characteristics and study design among our analysis, the initial findings from ARUBA, and the SAIVM AVM study are too great to clearly define a role for radiosurgery in management of unruptured AVMs. Nevertheless, we provide preliminary evidence from the collective experience of multiple tertiary referral centers for AVM treatment that radiosurgery can be acceptably offered as an alternative to medical therapy for a patient harboring an unruptured AVM.

\section{Predictors of AVM Radiosurgery Outcomes}

AVM volume has been consistently shown to have an inverse relationship with obliteration after GKRS across numerous studies. ${ }^{29,39}$ This finding was supported by our analysis, which found lower nidus volume to be an independent predictor of obliteration $(\mathrm{p}<0.001)$. As one would expect, higher radiosurgical dose delivered to the nidus improves the odds of obliteration. Prior analyses have shown a sigmoid dose-response curve for AVM obliteration. ${ }^{16}$ Higher margin dose was independently associated with obliteration in our multivariate model $(\mathrm{p}<0.001)$. Noneloquent location was also an independent predictor of obliteration $(\mathrm{p}=0.042)$. It is also possible that the lower obliteration rates of eloquent AVMs are indicative of the hesitancy of treating physicians to deliver higher margin doses to eloquent nidi. AVMs in eloquent locations were treated with significantly lower mean peripheral doses $(20.3 \pm 3.7 \mathrm{~Gy})$ than those in noneloquent locations (20.9 \pm $3.7 \mathrm{~Gy}, \mathrm{p}=0.001$ ).

In a number of prior AVM GKRS series, lower obliteration rates have been reported for embolized than for nonembolized nidi. ${ }^{6,29,39}$ In our study, lack of prior embolization was an independent predictor of obliteration ( $\mathrm{p}<$ 0.001). However, the effect of embolization on an AVM's biology and its response to GRKS is incompletely understood. ${ }^{27}$ The concern that liquid embolic agents may shield the nidus from the radiosurgical dose, by beam scattering or absorption, has been challenged by recent analyses..$^{5-7}$ Embolization has been shown to promote angiogenesis in AVMs, which may increase radioresistance and decrease obliteration rates. ${ }^{8,40}$ Additionally, due to general inability to precisely control the distribution of an embolic agent, AVM embolization can result in an irregular, diffuse nidus, which is difficult to radiosurgically target and thus prone to incomplete obliteration after treatment. ${ }^{41}$ Over time, there was a significant increase in rates of obliteration ( $p<0.001)$, suggesting that developments in GKRS technology and a refined understanding of the relationship between patient, AVM, and treatment factors and GKRS outcomes have, over time, yielded improved results.

\section{Validation of Grading Systems for AVM Radiosurgery}

Grading scales integrate individual predictors of outcome into an overall grade or score, which correlates with posttreatment outcomes and, ultimately, serves to guide management decisions. ${ }^{24,29,35}$ The first, and most widely used, AVM grading system was described by Spetzler and Martin. ${ }^{35}$ Although the Spetzler-Martin grade has been shown to correlate with AVM GKRS outcomes (AUC 0.60 ), it was originally proposed as a grading system for predicting operative morbidity and mortality after surgical intervention. ${ }^{21,35}$ Thus, it may not entirely reflect the factors that most significantly affect outcomes after AVM GKRS.

Subsequently, the RBAS was developed specifically for AVMs treated with radiosurgery and has been shown in our analysis to correlate with outcomes after GKRS (AUC 0.62 ), although its accuracy is comparable to that of the Spetzler-Martin grading system..$^{29,30,42}$ However, the use of a mathematical formula to calculate the RBAS, and its output as a continuous variable, may detract from the ease and practicality of its application. We recognized that the durable success of the Spetzler-Martin grading scale is rooted not only in the ability to predict outcomes but also in its simplicity. ${ }^{36}$ Therefore, the VRAS was designed to be a practical grading system analogous to the Spetzler-Martin grading scale, except with a focus on factors that enable the optimal prediction of outcomes for AVM radiosurgery rather than microsurgery. ${ }^{39}$ Interestingly, the VRAS components were made up of a combination of SpetzlerMartin (eloquence) and RBAS (volume) components. Additionally, the best multivariate predictors of outcome in this study also comprise the VRAS (eloquence, volume, and history of hemorrhage). In this multicenter validation of the VRAS in 2236 patients, which represents, by far, the largest AVM GKRS series ever compiled, we showed that the VRAS was not only significantly associated with favorable outcome after AVM GKRS ( $<<0.001)$, but also that it was superior to both the Spetzler-Martin grading scale and RBAS as a tool for assessing the suitability of an AVM nidus for treatment with GKRS (AUC 0.67).

The superior predictive capability of the VRAS score compared with the Spetzler-Martin grade and RBAS suggests that the composite radiological and clinical end point, favorable outcome, is affected more by AVM nidus volume, eloquent location, and prior AVM hemorrhage than AVM maximum diameter, deep venous drainage, deep AVM location, and patient age. While maximum diameter may be a sufficient indicator of nidus size for the purposes of predicting surgical outcomes, volume is more crucial for determining the optimal margin dose for radiosurgical targeting. ${ }^{15}$ Deep-seated AVMs and those with exclusively deep venous drainage are likely to be located in critical brain regions. However, these factors do not account for eloquent cortical AVMs with superficial venous drainage, which are more likely to be associated with symptomatic radiation-induced changes after radiosurgery ${ }^{43}$ Ruptured AVMs are more susceptible to hemorrhage during the latency period and thus unfavorable outcome, which is consistent with the effect of prior hemorrhage on an AVM's natural history. ${ }^{11-13}$ Advanced patient age has been shown to correlate with increased AVM hemorrhage risk and adversely affect surgical outcomes. ${ }^{22,23}$ However, increasing patient age does not appear to consistently confer a higher complication rate after radiosurgery, suggesting that the risk-to-benefit profile for radiosurgery remains favorable 
in the elderly AVM population. ${ }^{10}$ Although the VRAS is the simplest available grading system for predicting AVM radiosurgery outcomes, formulation of an individual assessment requires analysis of all patient, AVM, and treatment characteristics to determine outcomes following intervention.

\section{Study Limitations}

Although this study represents the largest series of AVM GKRS compiled to date, the analysis remains limited by the retrospective nature of the data collected from each of the participating institutions. Some of the data, particularly from the University of Pittsburgh Medical Center and the University of Virginia, were used to help construct prior radiosurgical AVM grading schemes. Thus, the overlapping cohorts represent a potential source for bias, but the lengths of follow-up in the current cohorts are longer than those used to derive the original grading systems.

In this study, $86 \%$ of cases of obliteration were confirmed by angiography. However, MRI was shown to be an adequate substitute for angiography in determining obliteration in the remaining patients. ${ }^{28,31}$ Thus, we believe that, despite the limitations, this study's multicenter design allows our findings to be generalizable to most AVM patients being considered for radiosurgical treatment.

\section{Conclusions}

GKRS for cerebral AVMs affords obliteration and avoids permanent complications in the majority of patients treated. Patient, AVM, and treatment parameters can be used to predict long-term outcomes following radiosurgery. Although all 3 currently used grading systems appear predictive of outcome, the VRAS provides a simple and reliable means to predict long-term outcome after GKRS.

\section{References}

1. Al-Shahi R, Bhattacharya JJ, Currie DG, Papanastassiou V, Ritchie V, Roberts RC, et al: Scottish Intracranial Vascular Malformation Study (SIVMS): evaluation of methods, ICD10 coding, and potential sources of bias in a prospective, population-based cohort. Stroke 34:1156-1162, 2003

2. Al-Shahi R, Warlow C: A systematic review of the frequency and prognosis of arteriovenous malformations of the brain in adults. Brain 124:1900-1926, 2001

3. Al-Shahi Salman R, White PM, Counsell CE, du Plessis J, van Beijnum J, Josephson CB, et al: Outcome after conservative management or intervention for unruptured brain arteriovenous malformations. JAMA 311:1661-1669, 2014

4. Altman DG: Practical Statistics for Medical Research. Boca Raton, FL: Chapman \& Hall/CRC, 1999

5. Andrade-Souza YM, Ramani M, Beachey DJ, Scora D, Tsao $\mathrm{MN}$, terBrugge $\mathrm{K}$, et al: Liquid embolisation material reduces the delivered radiation dose: a physical experiment. Acta Neurochir (Wien) 150:161-164, 2008

6. Andrade-Souza YM, Ramani M, Scora D, Tsao MN, terBrugge K, Schwartz ML: Embolization before radiosurgery reduces the obliteration rate of arteriovenous malformations. Neurosurgery 60:443-452, 2007

7. Bing F, Doucet R, Lacroix F, Bahary JP, Darsaut T, Roy D, et al: Liquid embolization material reduces the delivered radiation dose: clinical myth or reality? AJNR Am J Neuroradiol 33:320-322, 2012
8. Buell TJ, Ding D, Starke RM, Webster Crowley R, Liu KC: Embolization-induced angiogenesis in cerebral arteriovenous malformations. J Clin Neurosci 21:1866-1871, 2014

9. Crawford PM, West CR, Chadwick DW, Shaw MD: Arteriovenous malformations of the brain: natural history in unoperated patients. J Neurol Neurosurg Psychiatry 49:1-10, 1986

10. Ding D, Xu Z, Yen CP, Starke RM, Sheehan JP: Radiosurgery for cerebral arteriovenous malformations in elderly patients: effect of advanced age on outcomes after intervention. World Neurosurg 84:795-804, 2015

11. Ding D, Yen CP, Starke RM, Xu Z, Sheehan JP: Effect of prior hemorrhage on intracranial arteriovenous malformation radiosurgery outcomes. Cerebrovasc Dis 39:53-62, 2015

12. Ding D, Yen CP, Starke RM, Xu Z, Sheehan JP: Radiosurgery for ruptured intracranial arteriovenous malformations. J Neurosurg 121:470-481, 2014

13. Ding D, Yen CP, Xu Z, Starke RM, Sheehan JP: Radiosurgery for patients with unruptured intracranial arteriovenous malformations. J Neurosurg 118:958-966, 2013

14. Fine JP: A proportional hazards model for the subdistribution of a competing risk. J Am Stat Assoc 94:496-509, 1999

15. Flickinger JC, Kondziolka D, Pollock BE, Maitz AH, Lunsford LD: Complications from arteriovenous malformation radiosurgery: multivariate analysis and risk modeling. Int J Radiat Oncol Biol Phys 38:485-490, 1997

16. Flickinger JC, Pollock BE, Kondziolka D, Lunsford LD: A dose-response analysis of arteriovenous malformation obliteration after radiosurgery. Int J Radiat Oncol Biol Phys 36:873-879, 1996

17. Gray RJ: A class of K-sample tests for comparing the cumulative incidence of a competing risk. Ann Stat 16:1141-1154, 1988

18. Gross BA, Du R: Natural history of cerebral arteriovenous malformations: a meta-analysis. J Neurosurg 118:437-443, 2013

19. Hartmann A, Mast H, Mohr JP, Koennecke HC, Osipov A, Pile-Spellman J, et al: Morbidity of intracranial hemorrhage in patients with cerebral arteriovenous malformation. Stroke 29:931-934, 1998

20. Kano H, Kondziolka D, Flickinger JC, Yang HC, Flannery TJ, Niranjan A, et al: Stereotactic radiosurgery for arteriovenous malformations, Part 4: management of basal ganglia and thalamus arteriovenous malformations. J Neurosurg 116:33-43, 2012

21. Kano H, Lunsford LD, Flickinger JC, Yang HC, Flannery TJ, Awan NR, et al: Stereotactic radiosurgery for arteriovenous malformations, Part 1: management of Spetzler-Martin Grade I and II arteriovenous malformations. J Neurosurg 116:11-20, 2012

22. Kim H, Abla AA, Nelson J, McCulloch CE, Bervini D, Morgan MK, et al: Validation of the supplemented Spetzler-Martin grading system for brain arteriovenous malformations in a multicenter cohort of 1009 surgical patients. Neurosurgery 76:25-23, 2015

23. Kim H, Al-Shahi Salman R, McCulloch CE, Stapf C, Young WL: Untreated brain arteriovenous malformation: patientlevel meta-analysis of hemorrhage predictors. Neurology 83:590-597, 2014

24. Lawton MT, Kim H, McCulloch CE, Mikhak B, Young WL: A supplementary grading scale for selecting patients with brain arteriovenous malformations for surgery. Neurosurgery 66:702-713, 2010

25. Maruyama K, Kawahara N, Shin M, Tago M, Kishimoto J, Kurita H, et al: The risk of hemorrhage after radiosurgery for cerebral arteriovenous malformations. N Engl J Med 352:146-153, 2005

26. Mohr JP, Parides MK, Stapf C, Moquete E, Moy CS, Overbey JR, et al: Medical management with or without interventional therapy for unruptured brain arteriovenous malformations 
(ARUBA): a multicentre, non-blinded, randomised trial. Lancet 383:614-621, 2014

27. Mouchtouris N, Jabbour PM, Starke RM, Hasan DM, Zanaty M, Theofanis T, et al: Biology of cerebral arteriovenous malformations with a focus on inflammation. J Cereb Blood Flow Metab 35:167-175, 2015

28. O'Connor TE, Friedman WA: Magnetic resonance imaging assessment of cerebral arteriovenous malformation obliteration after stereotactic radiosurgery. Neurosurgery 73:761766, 2013

29. Pollock BE, Flickinger JC: Modification of the radiosurgerybased arteriovenous malformation grading system. Neurosurgery 63:239-243, 2008

30. Pollock BE, Flickinger JC: A proposed radiosurgery-based grading system for arteriovenous malformations. J Neurosurg 96:79-85, 2002

31. Pollock BE, Kondziolka D, Flickinger JC, Patel AK, Bissonette DJ, Lunsford LD: Magnetic resonance imaging: an accurate method to evaluate arteriovenous malformations after stereotactic radiosurgery. J Neurosurg 85:1044-1049, 1996

32. Pollock BE, Link MJ, Brown RD: The risk of stroke or clinical impairment after stereotactic radiosurgery for ARUBAeligible patients. Stroke 44:437-441, 2013

33. Rutledge WC, Abla AA, Nelson J, Halbach VV, Kim H, Lawton MT: Treatment and outcomes of ARUBA-eligible patients with unruptured brain arteriovenous malformations at a single institution. Neurosurg Focus 37(3):E8, 2014

34. Schneider BF, Eberhard DA, Steiner LE: Histopathology of arteriovenous malformations after gamma knife radiosurgery. J Neurosurg 87:352-357, 1997

35. Spetzler RF, Martin NA: A proposed grading system for arteriovenous malformations. J Neurosurg 65:476-483, 1986

36. Stapf C, Mast H, Sciacca RR, Berenstein A, Nelson PK, Gobin YP, et al: The New York Islands AVM Study: design, study progress, and initial results. Stroke 34:e29-e33, 2003

37. Stapf C, Mast H, Sciacca RR, Choi JH, Khaw AV, Connolly ES, et al: Predictors of hemorrhage in patients with untreated brain arteriovenous malformation. Neurology 66:1350-1355, 2006

38. Starke RM, Sheehan JP, Ding D, Liu KC, Kondziolka D, Crowley RW, et al: Conservative management or intervention for unruptured brain arteriovenous malformations. World Neurosurg 82:e668-e669, 2014

39. Starke RM, Yen CP, Ding D, Sheehan JP: A practical grading scale for predicting outcome after radiosurgery for arteriovenous malformations: analysis of 1012 treated patients. J Neurosurg 119:981-987, 2013

40. Sure U, Battenberg E, Dempfle A, Tirakotai W, Bien S, Bertalanffy $\mathrm{H}$ : Hypoxia-inducible factor and vascular endothelial growth factor are expressed more frequently in embolized than in nonembolized cerebral arteriovenous malformations. Neurosurgery 55:663-670, 2004
41. Valle RD, Zenteno M, Jaramillo J, Lee A, De Anda S: Definition of the key target volume in radiosurgical management of arteriovenous malformations: a new dynamic concept based on angiographic circulation time. J Neurosurg 109 Suppl:41-50, 2008

42. Wegner RE, Oysul K, Pollock BE, Sirin S, Kondziolka D, Niranjan A, et al: A modified radiosurgery-based arteriovenous malformation grading scale and its correlation with outcomes. Int J Radiat Oncol Biol Phys 79:1147-1150, 2011

43. Yen CP, Matsumoto JA, Wintermark M, Schwyzer L, Evans AJ, Jensen ME, et al: Radiation-induced imaging changes following Gamma Knife surgery for cerebral arteriovenous malformations. J Neurosurg 118:63-73, 2013

\section{Disclosures}

Drs. Pieper and Grills report having stock ownership in and serving on the Board of Directors of Greater Michigan Gamma Knife, and Dr. Grills reports receiving funding for non-study-related research from Elekta through her institution. Dr. Lunsford reports being a consultant and owning stock in Elekta.

\section{Author Contributions}

Conception and design: Sheehan, Starke, Pierce, Huang, Kondziolka, Rodriguez-Mercado, Grills, Barnett, Lunsford. Acquisition of data: Sheehan, Starke, Kano, Ding, Lee, Mathieu, Whitesell, Pierce, Huang, Kondziolka, Yen, Feliciano, Rodriguez-Mercado, Almodovar, Pieper, Grills, Silva, Abbassy, Missios, Barnett. Analysis and interpretation of data: all authors. Drafting the article: Sheehan, Starke, Ding, Lee, Mathieu, Whitesell, Yen, Feliciano, Rodriguez-Mercado, Pieper, Barnett. Critically revising the article: Sheehan, Starke, Kano, Ding, Lee, Mathieu, Whitesell, Pierce, Huang, Kondziolka, Yen, Feliciano, Rodriguez-Mercado, Almodovar, Pieper, Grills, Silva, Abbassy, Missios, Lunsford. Reviewed submitted version of manuscript: Sheehan, Starke, Kano, Ding, Lee, Mathieu, Whitesell, Pierce, Huang, Kondziolka, Yen, Feliciano, Rodriguez-Mercado, Almodovar, Pieper, Grills, Barnett. Statistical analysis: Starke. Administrative/technical/ material support: Sheehan, Kano, Ding, Lee, Mathieu, Whitesell, Pierce, Huang, Kondziolka, Yen, Feliciano, Rodriguez-Mercado, Almodovar, Pieper, Grills, Silva, Abbassy, Missios, Barnett, Lunsford. Study supervision: Sheehan, Starke, Kano, Mathieu, Pierce, Huang, Kondziolka, Yen, Feliciano, Rodriguez-Mercado, Almodovar, Pieper, Grills, Silva, Abbassy, Missios, Barnett, Lunsford.

\section{Correspondence}

Jason P. Sheehan, Department of Neurological Surgery, University of Virginia, Box 800212, Charlottesville, VA 22908. email: jsheehan@virginia.edu. 